Research Article

\title{
Evolution Law of Overburden Longitudinal Connected Fissures in a Shallowly Buried Coal Face with Thin Bedrock
}

\author{
Housheng Jia, ${ }^{1,2}$ Kun Pan $\left(D,{ }^{1}\right.$ Luyao Wang, ${ }^{1}$ Shaowei Liu, ${ }^{1,2}$ Mengxiong Fu (D, ${ }^{1}$ \\ and Xiang Ji ${ }^{1}$ \\ ${ }^{1}$ School of Energy Science and Engineering, Henan Polytechnic University, Jiaozuo 454003, China \\ ${ }^{2}$ Collaborative Innovation Center of Coal Work Safety, Jiaozuo, Henan 454003, China \\ Correspondence should be addressed to Mengxiong Fu; 756019387@qq.com
}

Received 13 July 2019; Accepted 8 November 2019; Published 19 December 2019

Academic Editor: Claudio Mazzotti

Copyright (C) 2019 Housheng Jia et al. This is an open access article distributed under the Creative Commons Attribution License, which permits unrestricted use, distribution, and reproduction in any medium, provided the original work is properly cited.

Longitudinal connected fissures in a shallowly buried coal face with thin bedrock are the main factor causing sand-burst accidents, water-burst accidents, and abnormal increases in water inflow. To understand the evolution of longitudinal connected fissures and propose method for controlling such fissures, 3-1 Coal of the Jinjie Coal Mine in Shendong Coal Group, China, was used as a case study. Physical simulation, numerical simulation, field measurements, and other measures were carried out to analyze thoroughly the opening and closure of fissures. At the same time, the stage characteristics of fissures evolution process are also obtained. The results indicate that when periodic weighting occurs, a longitudinal connected fissure starts to open. As the coal face moves on, the fissure expands gradually with the dynamic changes in horizontal force and rock dislocation; when the expansion reaches its limit, the key rock falls and the longitudinal connected fissure rapidly closes. With the advent of the next periodic weighting, the longitudinal connected fissure compacts further and the next longitudinal connected fissure appears. The formation of longitudinal connected fissures is described with reference to three factors: the advancement speed of the coal face, the holding power of the hydraulic support, and the filling degree of the goaf area, all of which can be easily controlled by engineering means. This study provides a basis for control of sand-burst accidents, water-burst accidents, and abnormal increase in water inflow in a shallow coal face with thin bedrock.

\section{Introduction}

The mining of coal resources in the Shendong area of China has made great contributions to the development of the national economy. The coal-bearing strata in this area are the Middle Jurassic Yanan Formation (Jxy). At present, most of the coalfields are shallowly buried with thin bedrock and thick unconsolidated layers and have the advantages of the coal seams being at a small angle, large coal thickness, and simple structure, which allow one-pass cutting coal mining, rapid advancement of the face, and other high-strength mining characteristics. However, in this mining environment and mining strength conditions, large-sized fissures occur. These fissures are longitudinal because of the fracturing of the shallowly buried, thin bedrock coal mass caused by mining. These longitudinal fissures connect the coal face with the unconsolidated layers, and even with the earth's surface. Therefore, these fissures are called longitudinal connected fissures. If the unconsolidated layers contain loose sand and/or an aquifer, there is a huge potential danger of sand bursts and water bursts, which seriously hinder the safety, coal yield, and efficiency of the mine [1-5]. In addition, the environment is extremely fragile because of desertification, drought, lowered rainfall, and sparse vegetation in this area. Surface water seeps into the goaf area if longitudinal connected fissures are present because of fracturing of the coal-bearing rock mass caused by mining, which brings about further deterioration of the ecological environment. For example, the development of coal mines around the Kuye River has resulted in its Muhegou, Wangqu, and Sanbulagou tributaries and other larger rivers being cut off since 1997. The Kuye River, a tributary of the Yellow River, was cut off for 75 days in 2000 and for 106 days in 2001. Hongjiannao, the largest inland lake in the Ordos 
Plateau with an area of $56 \mathrm{~km}^{2}$, has experienced a fall in water level of more than $2 \mathrm{~m}$ in 5 years. At the same time, the groundwater table within $50 \mathrm{~km}$ around the lake area dropped by $1.81 \mathrm{~m}$ [6-8]. However, the longitudinal connected fissures of a coal face should close as the coal face advances and the bedrock blocks migrate. Understanding the evolution of longitudinal connected fissures in a shallowly buried coal face with thin bedrock and proposal of corresponding control measures can significantly slow down or eliminate the occurrence of sand-burst accidents, waterburst accidents, and abnormal increases in water inflow. This is of great significance for the safe, environmentally friendly operation of mines under this type of geological conditions.

Failure of overburden under the influence of mining is an extremely complicated disaster mechanics problem. To understand the development of fissures in rock masses, Wang et al. [9-12] studied both the statistical self-similar fractal properties of a rock mass caused by mining and the evolution of the mining-caused fracture network of a rock mass with increasing mining width by means of similarmaterial models. Zhang et al. [13-15] established a model of flow through broken rock to analyze the relationship between fluids and fissure rock masses from multiple angles and provided a theoretical basis for prevention and control of water bursts and sand bursts at the microscopic level. Yu et al. [16-18] used mechanical analysis and numerical simulation to study the mechanical mechanism of undercutting cracks in the overburden strata of a shallowly buried coal seam and to explain the relationship between the stability conditions of key structural strata and mining damage in the overburden rock. Huang et al. [19-23] established a mechanical model of overlying strata based on the degree of fracture penetration by using the physical simulation results of the fracture characteristics of the upper strata in the overburden fracture zone; in addition; the factors influencing through-fracture of overburden strata were analyzed, providing a theoretical basis for determination of key strata and calculation of the height of the fractured zone through which water flows. Sun [24] established the dynamic variations of crack height in the overlying rock strata in a shallow basement by means of multivariate Geographic Information System fitting, and technology to control the longwall face to prevent the occurrence of sand bursts and water bursts was proposed with the aim of achieving water conservation. Great progress has been made in the development and evolution of overburden rock fissures, and there have been corresponding practical applications. However, there has been little research on the evolution of macroscopic longitudinal connected fissures. Therefore, this paper addresses the evolution of longitudinal connected fissures in shallowly buried thin bedrock using comprehensive research methods, establishes a mechanical model for opening and closure of longitudinal connected fissures in shallowly buried thin bedrock coal rock mass caused by mining based on the previous research results, and analyzes the mechanical mechanism and the key factors influencing opening and closure of longitudinal connected fissures in coal-bearing rock masses, thereby facilitating safe and environmentally friendly mining in shallowly buried thin bedrock.

\section{Geological Setting}

The Jinjie Coal Mine is located in Shenmu County, Yulin City, Shanxi Province, China. The location map of the Jinjie Coal Mine is presented in Figure 1. The Jinjie Coal Mine is fully equipped with longwall coal faces. Coal face 31104 of 31 Coal of the Jinjie Coal Mine was selected as the experimental site. The exploited coal is in a typical shallowly buried thin bedrock area and has a burial depth of about $110 \mathrm{~m}$. The coal seam is about $6 \mathrm{~m}$ thick, the load layers are about $65 \mathrm{~m}$ thick, and the bedrock is only about $45 \mathrm{~m}$ thick. The bedrock is composed of siltstone and fine-grained sandstone, which have high rock strength. The results of drilling through the roof strata of the tail entry in coal face 31104 are shown (Figure 2). At the same time, the area where the Jinjie Coal Mine is located is severely desertified, and there are no water bodies above the coal face.

According to the surveyed water data for coal face 31104, abnormal phenomena (water inflow at a rate $>200 \mathrm{~m}^{3} / \mathrm{h}$ ) often occur in the mining process because of the presence of strong aquifers in the overburden rock at 55-70 $\mathrm{m}$ depth, which affects the safety, high yield, and high efficiency of the mine. There is a close relationship between the water inflow and the periodic weighting of coal face 31104 (Figure 3 ). The standard of the periodic weighting is $6730 \mathrm{kN}$ based on the hydraulic support's sum of the average end-of-cycle resistance and its mean square deviation. The position of the periodic weighting in coal face 31104 has been confirmed from the change in the working resistance of the hydraulic support in the middle of the coal face. The amount of water inflow was obtained from the volume of the sump around the coal face. There were four instances of abnormal water flow in the $150 \mathrm{~m}$ monitoring roadway during periodic weighting (Figure 3). We deduce that the formation of longitudinal connected fissures through the overburden rock fractured during the mining process was the intrinsic cause of the abnormal water flow. Therefore, adjusting the mining parameters to control the evolution of longitudinal connected fissures will be an effective way to control abnormal water flow in the coal face.

\section{Physical Simulation of the Evolution of Longitudinal Connected Fissures}

3.1. Experimental Design. Taking into account the roof conditions and mining conditions of coal face 31104, we used a two-dimensional test plane and a model of the planar stress for the physical simulation test. The length, width, and height of the test bench were $1.8,0.16$, and $1.3 \mathrm{~m}$, respectively. From physical simulation, the size of the test bench, and field geological conditions, the geometric similarity ratio was $1: 100$ and the bulk density similitude ratio was $1: 1.6$. The simulated material consisted of river sand and mica with a small amount of gypsum and calcium carbonate. The parameters of the simulated rock thickness and physical and mechanical properties are provided 


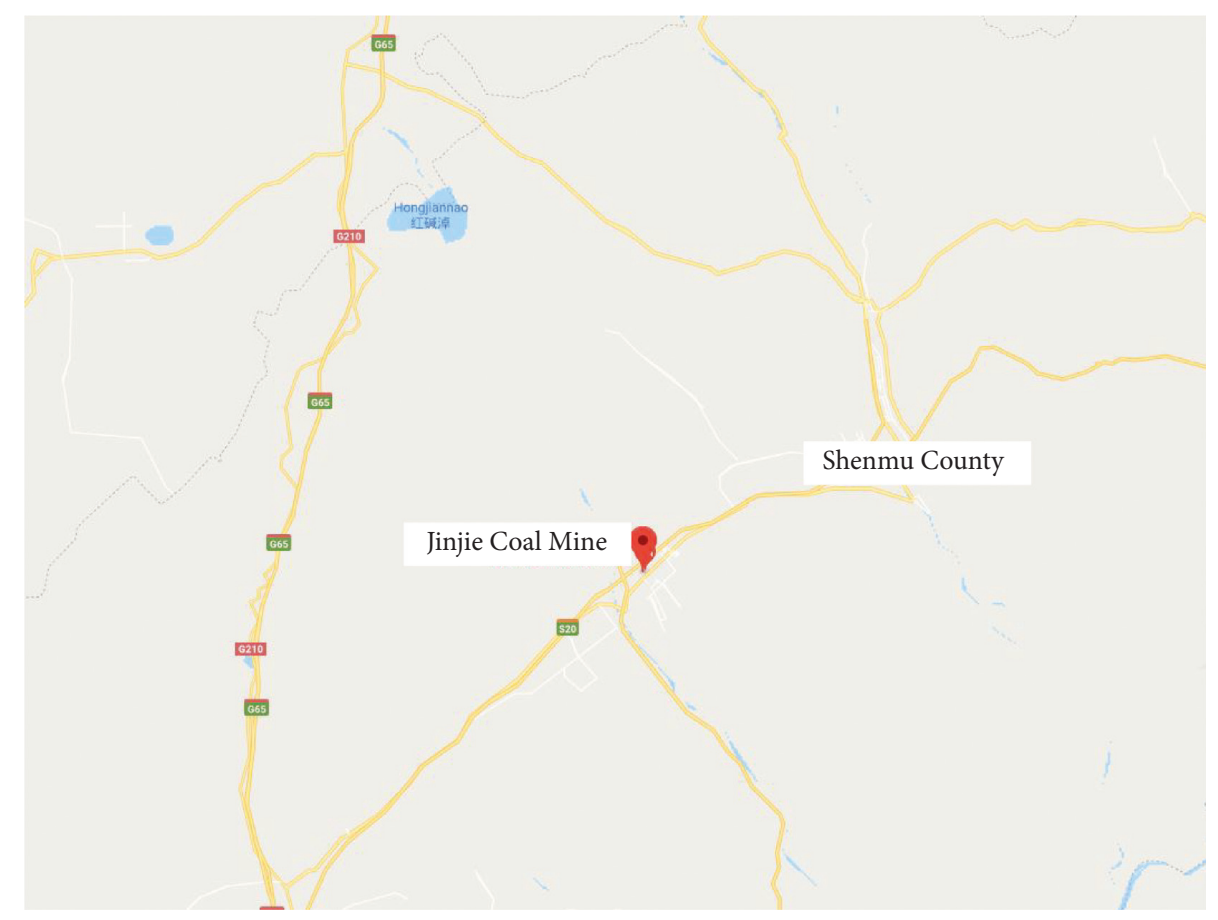

FIgure 1: The location map of the Jinjie Coal Mine.

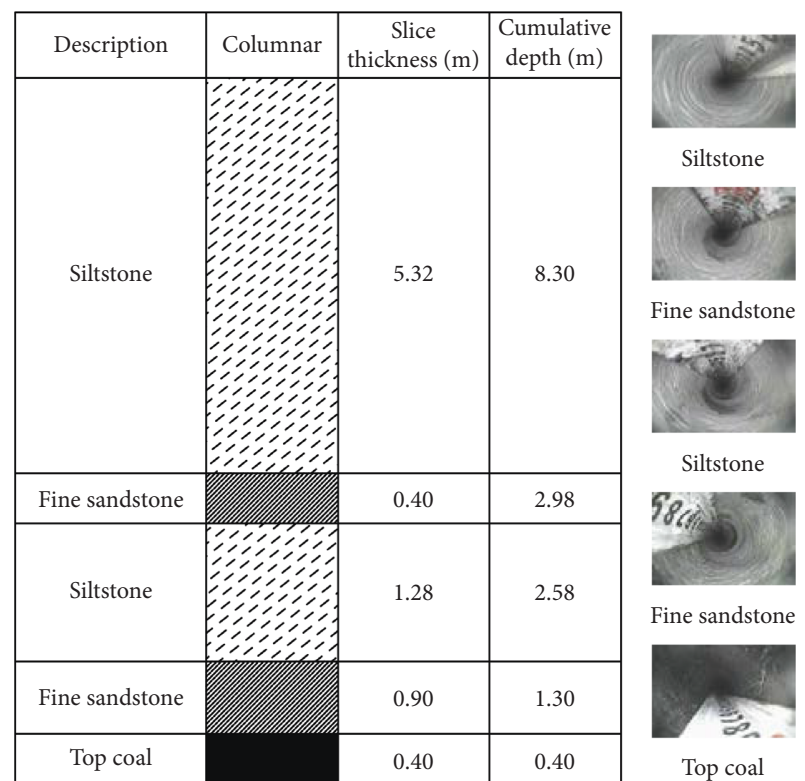

FIGURE 2: Roof structure in coal face 31104, borehole observation.

(Table 1). The aquifer in the unconsolidated layers was modeled in the physical simulation by gravel and fine sand of grain size $0.5-1.0 \mathrm{~cm}$ (Figure 4 ).

3.2. Experimental Process and Results. To avoid influence by the test bed boundary, mining started from $20 \mathrm{~cm}$ (equivalent to an actual length of $20 \mathrm{~m}$ ) and was mined by $5 \mathrm{~cm}$ (equivalent to an actual length of $5 \mathrm{~m}$ ) every 20 minutes during the mining process, thus simulating a quick mining process. For analytical convenience, the dimensions described below are actual rather than equivalent dimensions. When the coal face had advanced to $95 \mathrm{~m}$, the first collapse of the basic roof and the first episode of periodic weighting occurred. At the same time, the overburden bedrock broke off as a whole and the unconsolidated layers were also quickly affected, which caused a depression to form rapidly on the surface. The first weighting interval was $95 \mathrm{~m}$, greater than the value detected in the field. This was caused by the presence of unconsolidated layers with a lower mica content in the area, with the result that the unconsolidated layers had a lower ability to transmit load to the bedrock and the load on the bedrock was small at first and could be negligible in later experiments. The periodic weighting length was about $25 \mathrm{~m}$ for the formation of longitudinal connected fissures in the coal face. The evolution of longitudinal connected fissures in the bedrock layers is illustrated (Figure 5).

During the excavation of the coal face, the size of the fissure opening was regularly measured to understand the opening and closing of the longitudinal connected fissures in the shallowly buried thin bedrock. The sizes of the unconsolidated fissure in the bedrock through time are shown (Figure 6) and were referenced in the model for the physical simulation. When the coal face had advanced to $100 \mathrm{~m}$, the first periodic weighting started to occur (Figures 5(a) and 6(a)) and a longitudinal connected fissure approximately $0.22 \mathrm{~m}$ long appeared between the coal face and the unconsolidated layers. As the surface of the coal face advanced, the bedrock blocks gradually turned toward the goaf area. When the coal face had advanced to $120 \mathrm{~m}$, the bedrock blocks turned to the limit (Figures 5(b) and 6(b)) and the longitudinal connected fissure reached its maximum length of about $1.53 \mathrm{~m}$. The 


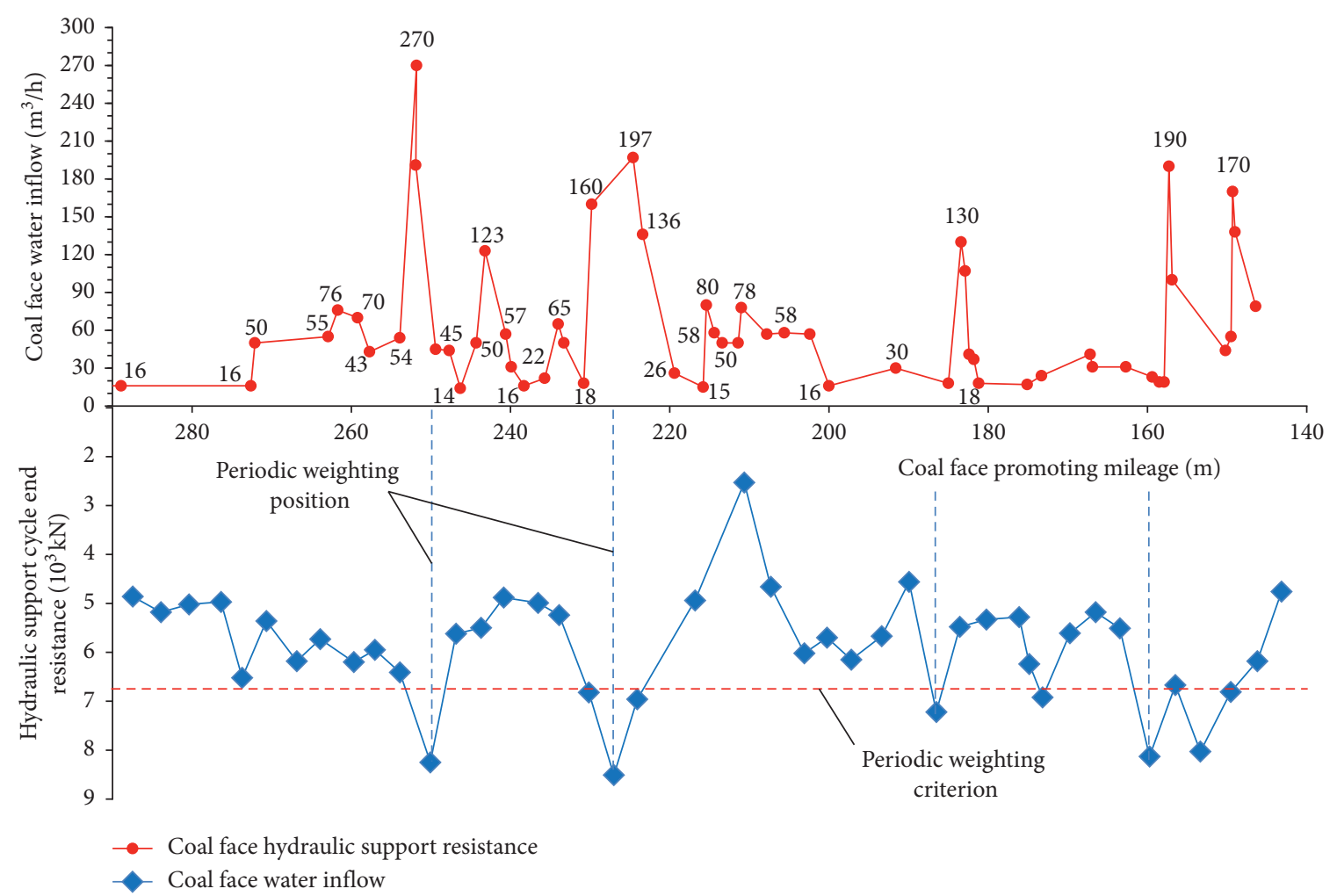

FIGURE 3: Monitoring results of periodic weighting and water inflow in coal face 31104.

TABLE 1: Thickness and physical-mechanical properties of analog strata.

\begin{tabular}{|c|c|c|c|c|c|}
\hline & Layer & Lithology & Observed thickness (m) & Compressive strength (MPa) & Bulk density $\left(\mathrm{kg} / \mathrm{m}^{3}\right)$ \\
\hline 1 & & Epipedon a & 8.5 & 5 & 2300 \\
\hline 2 & & Epipedon b & 20.0 & 5 & 2250 \\
\hline 3 & Unconsolidated layers & Epipedon c & 11.0 & 5 & 2300 \\
\hline 4 & & Aquifer & 17.0 & 5 & 2350 \\
\hline 5 & & Sandy mudstone & 8.5 & 16 & 2420 \\
\hline 6 & & Gritstone & 13.5 & 67 & 2740 \\
\hline 7 & & Siltstone & 12.5 & 45 & 2700 \\
\hline 8 & & Fine sandstone & 8.0 & 40 & 2620 \\
\hline 9 & Base rock & Siltstone & 8.4 & 30 & 2700 \\
\hline 10 & & Fine sandstone & 0.4 & 35 & 2620 \\
\hline 11 & & Siltstone & 1.3 & 30 & 2700 \\
\hline 12 & & Fine sandstone & 0.9 & 25 & 2570 \\
\hline 13 & Coal & Coal seam & 6.0 & 11.5 & 1500 \\
\hline
\end{tabular}

longitudinal connected fissure became a passage for sand bursts and water bursts and thus had the potential to result in an accident at this time. When the coal face had advanced to $125 \mathrm{~m}$, the bedrock was broke off behind the hydraulic support and significant dislocation occurred because the bottom corner of the rotating rock could not support the force of overburden fracturing (Figures 5(c) and 6(c)). The longitudinal connected fissure closed quickly to a length of about $0.3 \mathrm{~m}$ with the appearance of the next longitudinal connected fissure. When the coal face had advanced to $135 \mathrm{~m}$, the longitudinal connected fissure was completely compacted (Figures 5(d) and 6(d)) because of extrusion of the adjacent bedrock. Considering the effect of expansibility at the time of overburden fracturing and the unevenness of the fissure's open face, there was no danger of sand-burst and water-burst accidents at this time. This shows the final model after the end of coal face advancement (Figure 7), and there was no great difference in the size of the periodic weighting length caused by three longitudinal connected fissures. Moreover, longitudinal connected fissures connected the coal face with the unconsolidated layers and even the earth's surface because of the movement of the overburden.

On the basis of measurements of the fissure size as the coal face advanced, from the statistical results of the fissure size, the evolution process of longitudinal connected fissures is very significant in terms of time and space, 


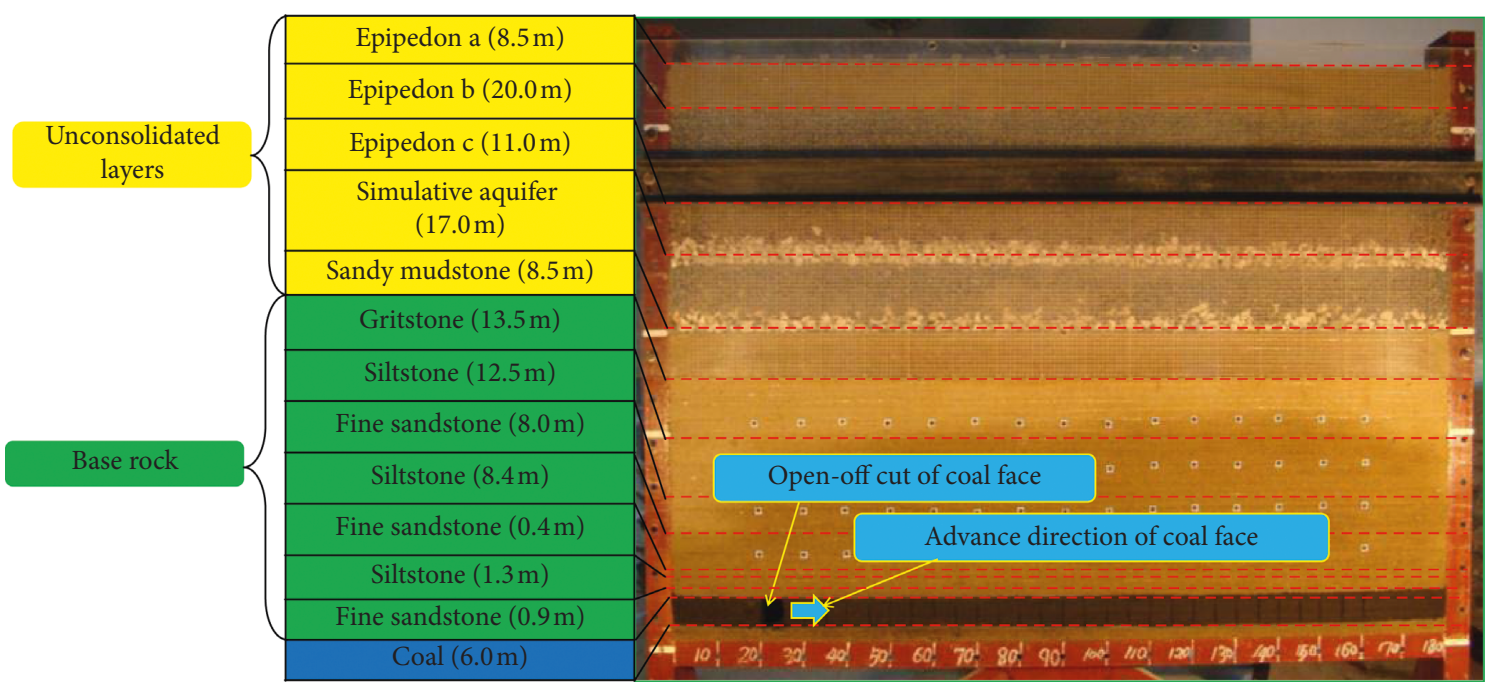

Figure 4: Physical simulation model.

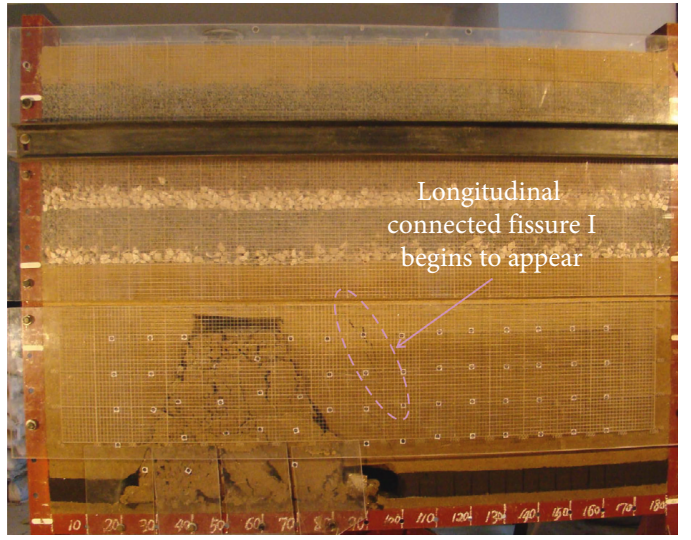

(a)

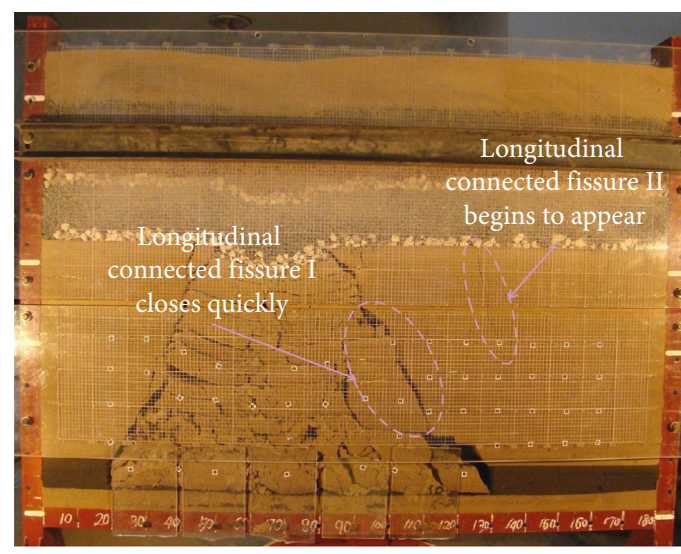

(c)

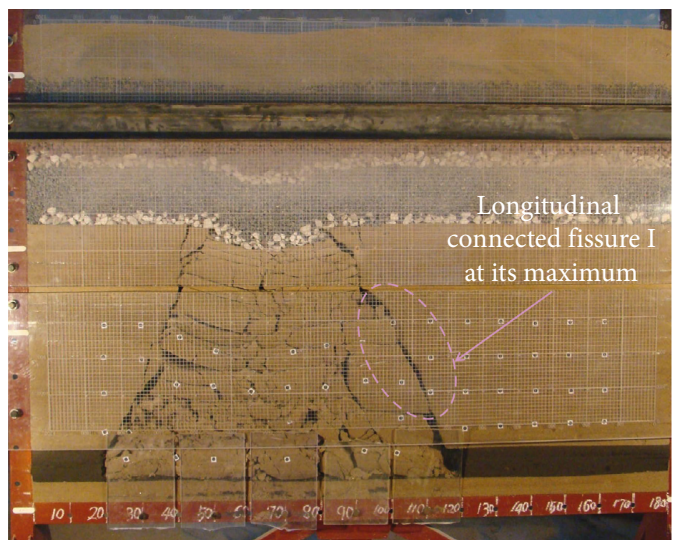

(b)

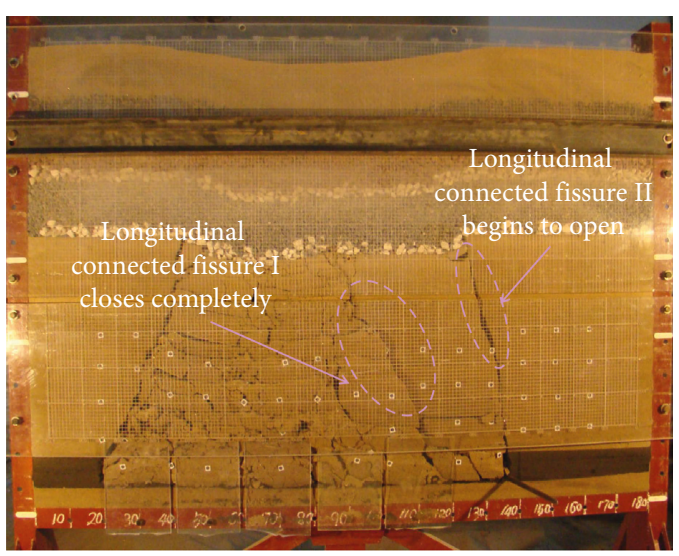

(d)

FiguRE 5: Entire opening and closing process of a longitudinal connected fissure in bedrock. (a) Fissure begins to open. (b) Fissure at its maximum extent. (c) Fissure closes quickly. (d) Fissure closes completely.

especially in relation to the periodic weighting position. The evolution of a longitudinal connected fissure can be divided into four stages, from inoculation to complete compaction (Figure 8):
(1) After the initial collapse of the basic roof, longitudinal fractures began to appear in front of the coal face and gradually extended, connecting the coal face with the unconsolidated layer. Periodic weighting 


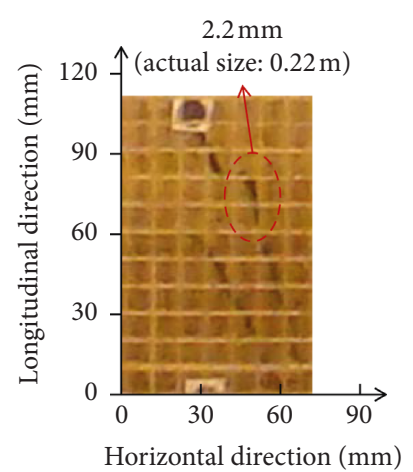

(a)

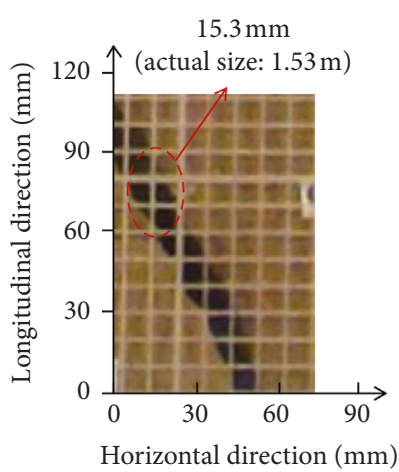

(b)

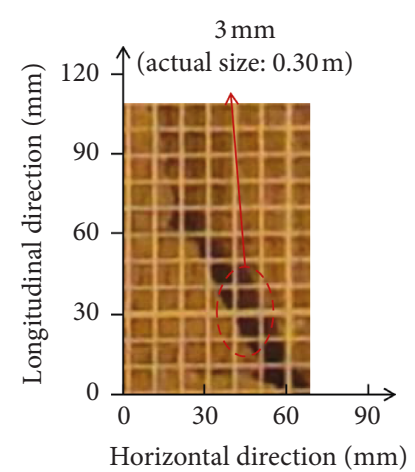

(c)

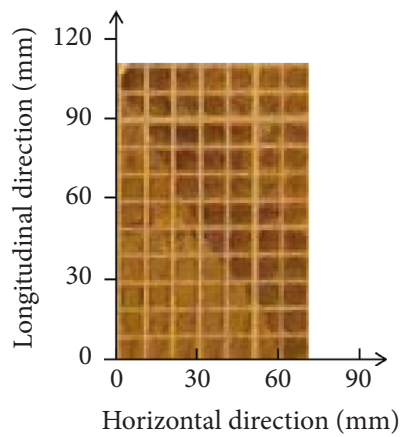

(d)

Figure 6: Measurements of a longitudinal connected fissure in bedrock. (a) Fissure inoculation. (b) Fissure opening. (c) Fissure closing. (d) Fissure compaction.

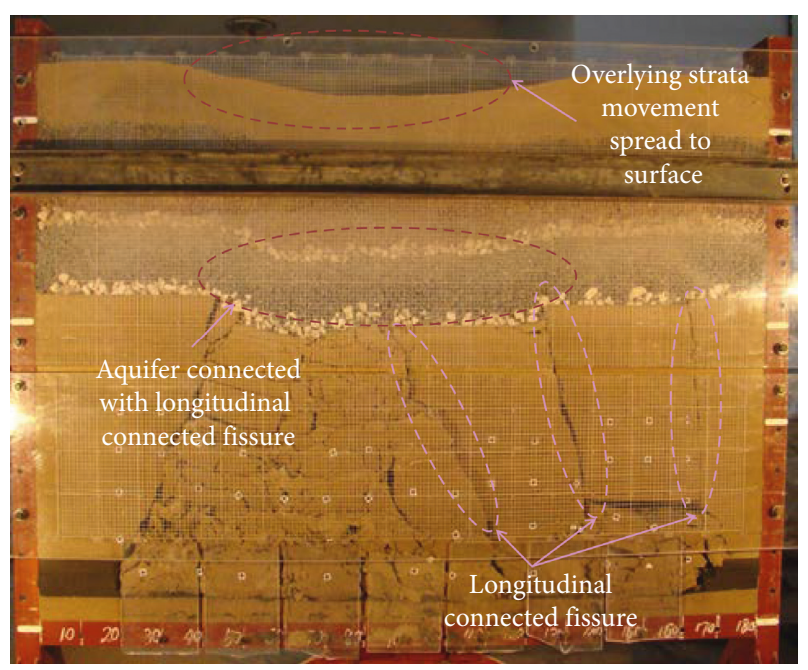

FIgURE 7: Model after the end of coal face advancement.

was initiated. This is called the fissure inoculation stage.

(2) During initial periodic weighting, the bedrock rotated in the direction of the goaf area with the longitudinal connected fissure as the axis, causing the fissure to increase in size continuously until the limit. A higher mining height, smaller periodic weighting length, and smaller bulking coefficient of the breaking layers will result in a larger fissure size. This is the fissure opening stage.

(3) As the coal face advanced, the rock mass formed by the first periodic weighting inevitably broke off at the back of the hydraulic support, especially if the mining height was large. The breaking of the bedrock and its counterrotation, together with the effects of expansibility of the collapsing rock and the unevenness of the fissure's surface, caused the longitudinal connected fissure to close rapidly and the next longitudinal connected fissure to appear. This is the stage of rapid fissure closure.

(4) With the beginning of the next periodic weighting, the longitudinal connected fissure closed further because of extrusion between the adjacent bedrock and the caved rock from the rotated motion. This is the fissure compaction stage.

\section{Numerical Analysis of the Opening and Closing Process of Longitudinal Connected Fissures}

As another means of understanding the opening and closing process of longitudinal connected fissures in a shallowly buried coal face with thin bedrock and the evolution of longitudinal connected fissures, we set up a two-dimensional Universal Distinct Element Code numerical model with a width of $400 \mathrm{~m}$ and a height of $110 \mathrm{~m}$ based on geological data (Table 1) and the field. The front, back, and side loads of the model were 1.2 times the vertical load. The initial stress state is as follows: the $Z$ direction is loaded with $2.75 \mathrm{MPa}$, and the $X$ and $Y$ directions are loaded with $3.30 \mathrm{MPa}$. The bottom boundary imposed a vertical constraint; the left and right boundaries imposed a horizontal constraint. The model of the coal included 1534 zones. The model of the base rock included 492 zones. The model of the unconsolidated layers included 4404 zones. We used the Mohr-Coulomb model for the constitutive relation of the surrounding rock. The rock mechanical parameters used in the numerical analysis are provided (Table 2).

According to the results of the numerical simulation, the periodic weighting length is $24 \mathrm{~m}$. The simulation results when the coal face was excavated to $200 \mathrm{~m}$ are shown (Figure 9). The structural state and degree of fracturing of the basic roof during coal face advancement determined the development and expansion of the longitudinal connected fissure. During periodic weighting, the size of the longitudinal connected fissure in the overburden increased because of rotation of the basic roof rock. As a result of breakage and reverse rotation in the fractured overburden, the dissociative unit bodies containing the longitudinal connected fissure contracted again, meaning that the longitudinal connected fissure closed. When the next periodic weighting took place, the unit bodies that had contracted were partially embedded under the action of the rotary extrusion of the adjacent fractured overburden, which caused further closure of the longitudinal connected fissure. The numerical 


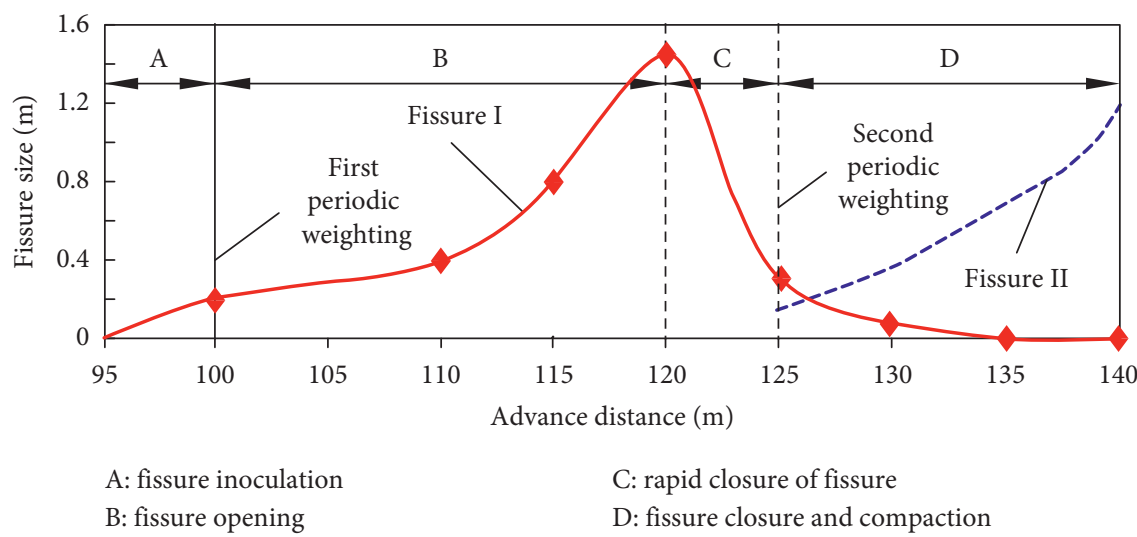

FIgURE 8: Changes in the size of a longitudinal connected fissure in bedrock through time.

TABLE 2: Rock mechanical parameters used in the numerical analysis.

\begin{tabular}{|c|c|c|c|c|c|c|c|c|c|}
\hline Lay & & Lithology & Observed thickness (m) & $\gamma\left(\mathrm{kg} / \mathrm{m}^{3}\right)$ & $K(\mathrm{GPa})$ & $G(\mathrm{GPa})$ & $C(\mathrm{MPa})$ & $\varphi\left({ }^{\circ}\right)$ & $\sigma(\mathrm{MPa})$ \\
\hline 1 & \multirow{5}{*}{ Unconsolidated layers } & Epipedon a & 8.5 & 2300 & 5.0 & 3 & 2.2 & 24 & 0.8 \\
\hline 2 & & Epipedon b & 20.0 & 2250 & 6.0 & 3.5 & 2.5 & 25 & 1.0 \\
\hline 3 & & Epipedon c & 11.0 & 2300 & 6.0 & 3.5 & 3.0 & 27 & 1.5 \\
\hline 4 & & Aquifer & 17.0 & 2350 & 8.0 & 4.5 & 4.5 & 29 & 2.0 \\
\hline 5 & & Sandy mudstone & 8.5 & 2420 & 8.0 & 5.0 & 5.0 & 29 & 2.5 \\
\hline 6 & \multirow{7}{*}{ Base rock } & Gritstone & 13.5 & 2740 & 15.5 & 9.6 & 6.2 & 31 & 3.2 \\
\hline 7 & & Siltstone & 12.5 & 2700 & 14.3 & 9.0 & 6.0 & 30 & 3.0 \\
\hline 8 & & Fine sandstone & 8.0 & 2620 & 18.3 & 11.5 & 7.0 & 35 & 4.5 \\
\hline 9 & & Siltstone & 8.4 & 2700 & 14.3 & 9.0 & 6.0 & 30 & 3.0 \\
\hline 10 & & Fine sandstone & 0.4 & 2620 & 18.3 & 11.5 & 7.0 & 30 & 4.5 \\
\hline 11 & & Siltstone & 1.3 & 2700 & 14.3 & 9.0 & 6.0 & 30 & 3.0 \\
\hline 12 & & Fine sandstone & 0.9 & 2620 & 18.3 & 11.5 & 7.0 & 35 & 4.5 \\
\hline 13 & Coal & Coal seam & 6.0 & 1500 & 7.0 & 4.5 & 4.0 & 28 & 1.5 \\
\hline
\end{tabular}

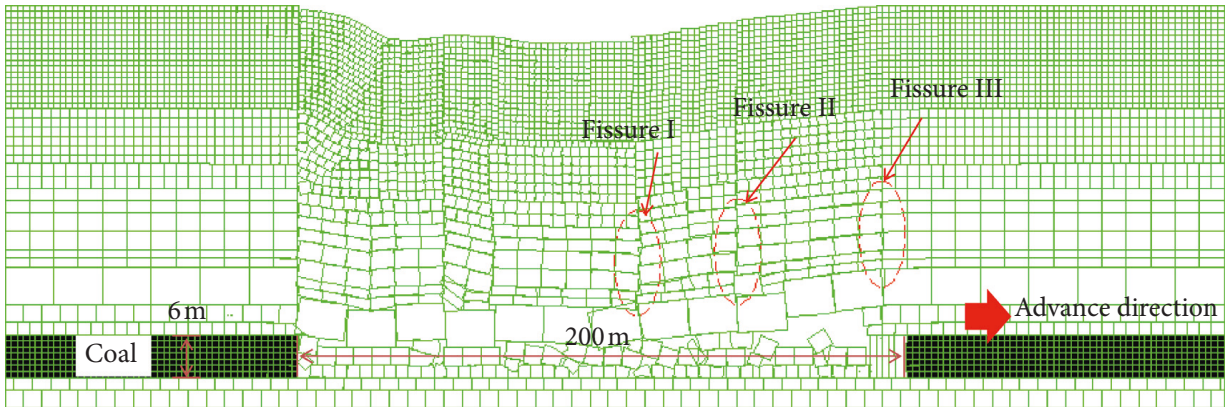

FIGURE 9: Results of the numerical simulation of the opening and closing process of a longitudinal connected fissure.

calculation of the opening and closing process of a longitudinal connected fissure in the coal face yielded the same results as the physical simulation. The simulation results for three longitudinal connected fissures are shown (Figure 10).

\section{Opening and Closing of Longitudinal Connected Fissures in the Field}

At present, there is no direct method for observing the evolution of overburden longitudinal connected fissures in a coal face. However, in a coal face in shallowly buried thin bedrock and a thick unconsolidated layer, a longitudinal connected fissure in the overburden quickly connects to the surface. The evolution of the overburden longitudinal connected fissure can be inferred from the opening and closure of fissures in the surface unconsolidated layer. We selected the 31103 coal face of the Jinjie mine to study the different stages of the longitudinal connected fissures. The bedrock overlying the coal face is $25-35 \mathrm{~m}$ thick and is situated at about $90 \mathrm{~m}$ depth. Taking into account the thickness of the unconsolidated layers and the topography of the earth's surface, longitudinal connected fissures were selected on the surface 270-340 m away from the coal face. During observation, only surface fissures that were consistent with the direction of the 


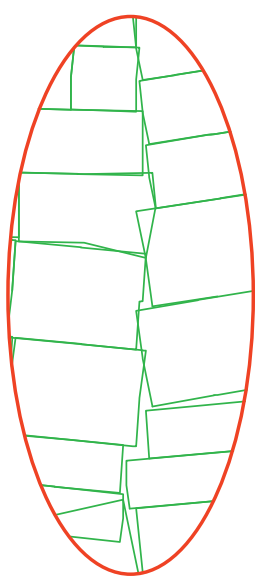

(a)

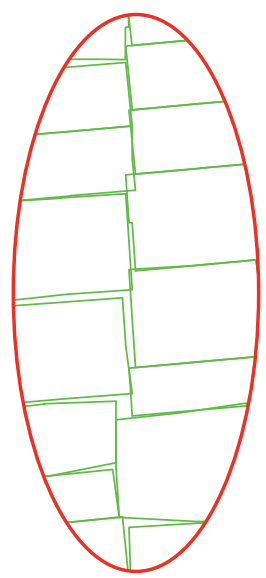

(b)

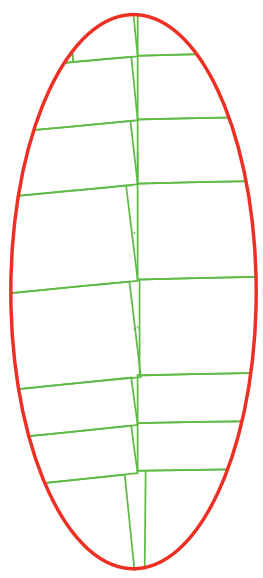

(c)

FIGURE 10: Enlargement of the simulation results of a longitudinal connected fissure. (a) Fissure I compaction. (b) Fissure II compaction. (c) Fissure III compaction.

coal face and were at least $20 \mathrm{~cm}$ long were measured to reflect the opening and closure of the longitudinal connected fissures in the overburden. Two stations located $45 \mathrm{~m}$ apart were situated in a location where there were signs of longitudinal connected fissures. The results of real-time monitoring of longitudinal connected fissures in the 31103 coal face are illustrated (Figure 11).

The results for Station A are described below: when the coal face had advanced to $277 \mathrm{~m}$ from the setup entry, the longitudinal connected fissure ( $\sim 0.03 \mathrm{~m}$ in length) started to open as shown in Figure 12(a). When the coal face had advanced to $289 \mathrm{~m}$ from the setup entry, the longitudinal connected fissure opened to its maximum size (about $0.45 \mathrm{~m}$ long; Figure 12(b)). When the coal face had advanced to $293 \mathrm{~m}$ from the setup entry, the longitudinal connected fissure began to close (to $\sim 0.15 \mathrm{~m}$ long) with the breaking off of the overburden (Figure 12(c)). When the coal face had advanced to $297 \mathrm{~m}$ from the setup entry, the longitudinal connected fissure had completely closed, and the size of the broken rock was $0.25 \mathrm{~m}$ (Figure 12(d)). The evolution of the surface fissures at Station B was basically similar to that at Station A (Figures 12(e)-12(h)). The open or closed states of the longitudinal connected fissures at Station B were more obvious: the maximum size of the surface fissure was $0.51 \mathrm{~m}$ and the size of the broken overburden was $0.53 \mathrm{~m}$ when the fissure had closed completely. For the relationship between opening, growth, and closure of the fissure in the field and the periodic weighting, the results from the field were basically consistent with those of the simulation experiments.

\section{Mechanical Analysis and Factors Influencing Opening and Closure of Longitudinal Connected Fissures}

6.1. Mechanical Analysis of the Opening and Closure of Longitudinal Connected Fissures. From the results of physical simulation, numerical analysis, and field measurements, the key rock block that determines the periodic weighting will be broken up before the next periodic weighting during advancement of the shallowly buried coal face with thin bedrock. The structure formed by the rock breakage could be regarded as a "step voussoir beam" structure affected by the horizontal force and the downward shear force at the front corner of the key rock (Figure 13) $[25,26]$. Referring to the structural model, the opening and closure of the longitudinal connected fissure is taken as the entry point. Assume that the hinge joint between rock $M$ and rock $N$ is located in the back of the hydraulic support and the broken rock is completely located above in the collapsed rock. The broken rock is completely located on the caved rock, and rock $M$ is supported by rock $N$ at point $C$. Rock $N$ is basically in a compacted state at this time.

The downward movement of rock $M$ in the goaf area is given by

$$
w=m-\left(K_{p}-1\right) \sum h_{z}-b
$$

where $\sum h_{z}$ is the thickness of the immediate roof $(\mathrm{m}), m$ is the mining height $(\mathrm{m}), b$ is the amount of rock dislocation (m), and $K_{p}$ is the rock coefficient of bulk increase.

The maximum turning angle of rock $M$ is given by

$$
\theta_{\text {max }}=\arcsin \frac{w}{l}=\arcsin \frac{m\left(K_{p}-1\right) \sum h_{z}-b}{2} .
$$

The height $a$ of the extrusion interface of the rock corner can be derived by means of equation (3) using the geometric contact relationship of rock rotation. The position of horizontal force $T$ is at 0.5 a because of the plastic contact relationship between the rocks:

$$
a=\frac{h-l \sin \theta}{2}
$$

$l_{M}=l_{N}=l$ because the same force conditions operate as for periodic fracturing of the bedrock. The pressure on rock $N$ is equal to the force of the gangue on rock $N$ (Figure 12), meaning that $R_{2}=P_{2}$. The shear between the rock and the 


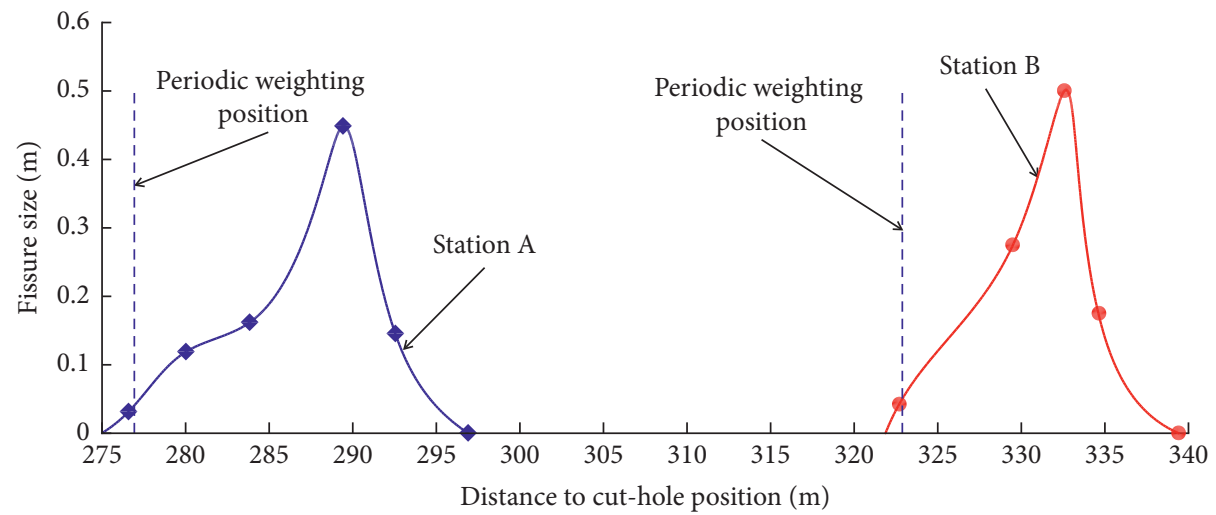

Figure 11: Measurements of the longitudinal connected fissures of the 31103 coal face.

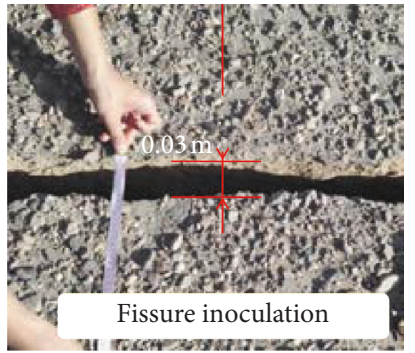

(a)

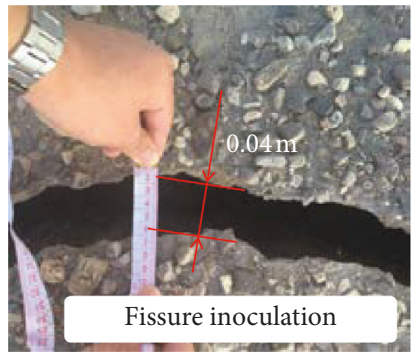

(e)

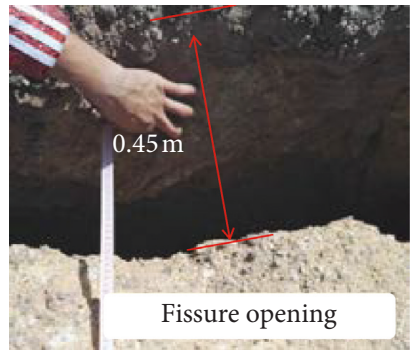

(b)

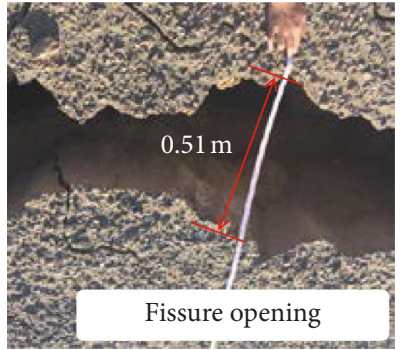

(f)

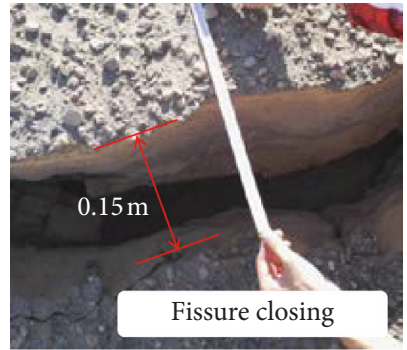

(c)

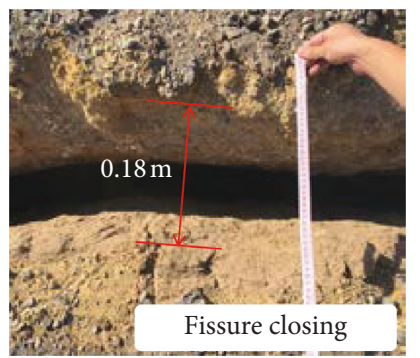

(g)

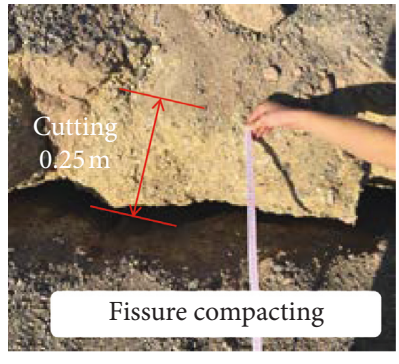

(d)

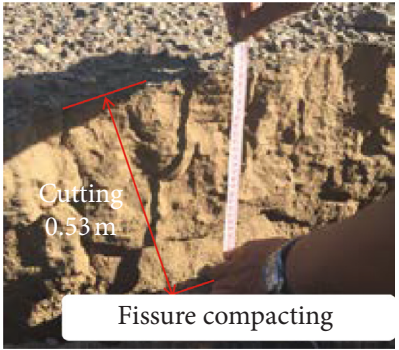

(h)

Figure 12: Field photographs and sizes of the longitudinal connected fissures of the 31103 coal face. (a) Station A fissure inoculation. (b) Station A fissure opening. (c) Station A fissure closing. (d) Station A fissure compacting. (e) Station B fissure inoculation. (f) Station B fissure opening. (g) Station B fissure closing. (h) Station B fissure compacting.

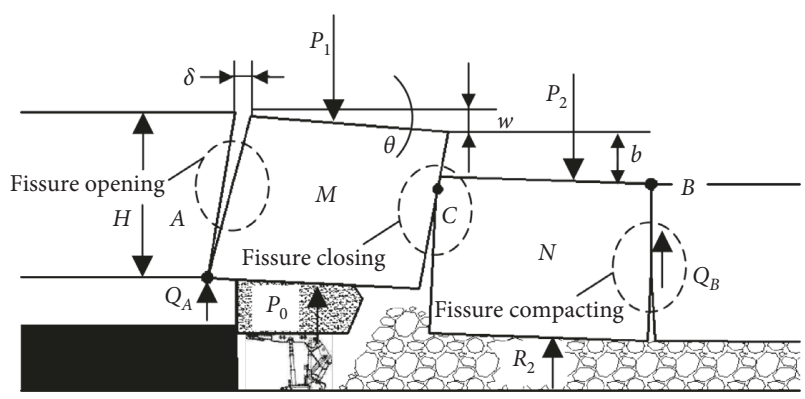

FIGURE 13: Mechanical model for opening and closing of a longitudinal connected fissure.

unbroken rock in the front can be regarded as the pressure on the rock $M$ in this structure. The horizontal force $T$ is given by

$$
T=\frac{l\left(P_{1}-P_{0}\right)}{2(H-a-w)}=\frac{l\left(P_{1}-P_{0}\right)}{H+l \sin \theta-m+\left(K_{p}-1\right) \sum h_{z}+b},
$$

where $P_{0}$ is the support power of the hydraulic support $(\mathrm{kN})$, $P_{1}$ is the pressure of the rock $M(\mathrm{kN})$, and $H$ is the height of the rock $(\mathrm{m})$.

According to the geometric relationship (Figure 12), the size of the longitudinal connected fissure is given by

$$
\delta=H \sin \theta=\frac{H}{l}\left[\frac{l\left(P_{1}-P_{0}\right)}{T}+m-\left(K_{p}-1\right) \sum h_{z}-b-H\right] .
$$

Periodic weighting can be considered as periodic breaking of cantilevered bedrock. The periodic weighting 
length $l$ is determined by the periodic breaking of cantilevered bedrock and is given by

$$
l=H \sqrt{\frac{R_{t \max }}{3 q}},
$$

where $R_{t \text { max }}$ is the limited tensile strength (MPa) and $q$ is the uniform load above the rock beam $(\mathrm{kN} / \mathrm{m})$.

In summary, the emergence of longitudinal connected fissures in a coal face begins with periodic fracturing of the key rock. The size of the longitudinal connected fissure gradually increases with changes in the horizontal force of the fractured block and the dislocation between the blocks as the coal face sequentially advances. The key rock controlling the periodic weighting breaks up when the fissure reaches its maximum size, and the fissure closes quickly at the same time. This fissure will close further during opening of the next longitudinal connected fissure.

\subsection{Factors Influencing the Opening and Closing Process of} Longitudinal Connected Fissures. According to equations (5) and (6), the evolution of longitudinal connected fissures in a coal face mainly depends on factors such as the periodic weighting length, the filling degree of the goaf area, the mechanical properties of the strata, the thickness of the strata, and the holding power of the hydraulic support. For specific engineering geological conditions, the mechanical properties and thickness of the strata are known and the periodic weighting length can be determined by theoretical calculation. The effect of the opening and closing of longitudinal connected fissures can be explored by considering the advancement speed of the coal face, the filling degree of the goaf area, and the holding power of the hydraulic support, which can control and prevent danger from sand bursts and water bursts.

6.2.1. Speed of Coal Face Advancement. The size of the periodic weighting length in the basic roof affects the rotation angle of the fractured rock. A larger periodic weighting length results in a smaller turning angle and less development of longitudinal connected fissures in the coal face. For a coal face with a long periodic weighting length, the longitudinal connected fissures can be considered as noncontinuous when the rock's degree of expansibility is higher in fractured bedrock and the fissure's surface is irregular; in this case, the advancement speed of the coal face can be decreased. However, in general, the periodic weighting length in a shallowly buried coal face with thin bedrock is small, and opening of longitudinal connected fissures is inevitable. Controlling the advancement speed of the coal face is crucial. Application of grouting and other measures to plug longitudinal connected fissures is effective before periodic weighting. Measures are not required if the fissures close rapidly after periodic weighting. At the same time, appropriately speeding up the advancement speed of the coal face can prevent the coal face stopping in a position that allows maximum opening of longitudinal connected fissures, which can reduce the danger of sand-burst and water-burst incidents. This finding also explains why sandburst and water-burst accidents generally occur during trial mining or with a variable advancement speed in many shallowly buried coal faces with thin bedrock. When the coal face is in Position A, it is necessary to put an end to stop advancing and to speed up the coal face speed as much as possible (Figure 14). When the coal face is advanced to Position B and the longitudinal connected fissure is closing, normal advancement and other work are permitted.

6.2.2. Holding Power of the Hydraulic Support. Engineering practical experience demonstrates that whole breakage of bedrock is the basic form of rock mass fracturing caused by mining in shallowly buried thin bedrock and is unavoidable. However, increasing the holding power of the hydraulic support can effectively delay the expansion of longitudinal connected fissures. Therefore, in engineering practice, the action area and the working resistance of the hydraulic support should be adjusted to slow down the turning degree of the rock prior to bedrock breaking so that the longitudinal connected fissures are directly cut off at a smaller size and the fissures close quickly. In addition, the maintenance and grouting processes that will pause the advancement of the coal face should be arranged during the closing stage of the fissure. Furthermore, from the geometrical relationship between the coal face roof and the support beam, it is necessary to pay attention to the effect of the supporting force in the coal face roof and weaken the effect of the support beam.

6.2.3. Filling Degree of the Goaf Area. The filling degree of the goaf area directly determines the turning deformation space of the fracturing bedrock. The turning degree of the fracturing bedrock also indirectly determines the maximum fissure opening size of the longitudinal connected fissure. This parameter is directly related to the filling degree of the strata under the bedrock and the mining height. For thin, medium-thick, and larger mining depth coal seams, backfill mining or limited height mining can be implemented to reduce the fracturing block deformation space in bedrock. For the fully mechanized top coal caving face, it is possible to carry out interval coal caving or reduce the amount of coal caving. It can control the development of longitudinal connected fissures and the maximum opening size of the fissure. However, for a thick coal seam coal face with shallowly buried and thin bedrock in high-strength mining, this would be difficult and expensive. One-pass cutting coal mining, fast advancement, and other methods can be used to prevent sand bursts and water bursts. The key point is that effective measures to promote closure of the longitudinal connected fissures should be applied as much as possible.

\section{Field Experimental of the Longitudinal Connected Fissure Control}

According to the analysis of the factors influencing the evolution of longitudinal connected fissures, field experimental of longitudinal connected fissure control was 


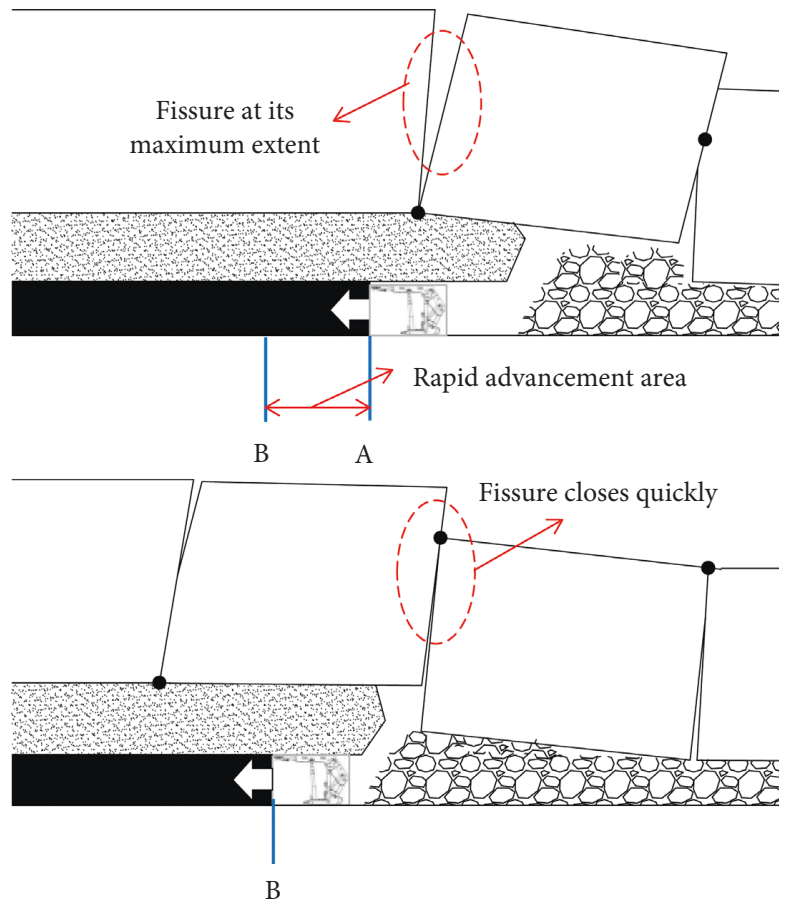

FIgURE 14: Schematic diagram of the coal face rapid advancement area.

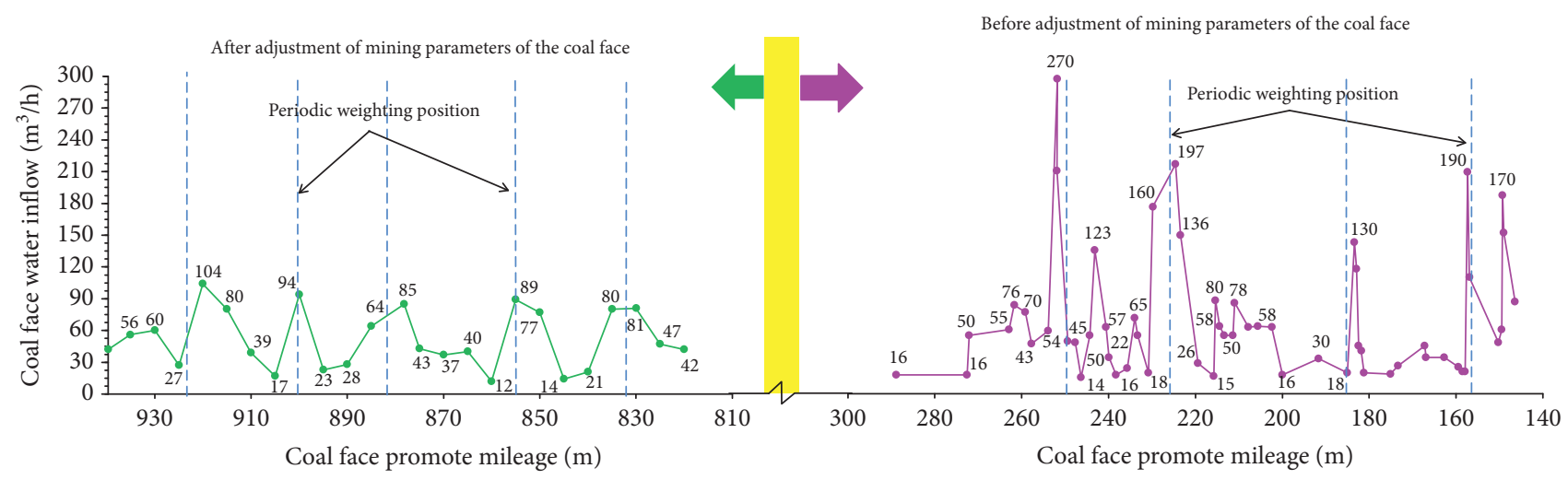

FigURE 15: Monitoring results of water inflow before and after adjustment of coal face parameters.

conducted in 720 950 $\mathrm{m}$ water-rich area of Coal face 31104 of 3-1 Coal of the Jinjie Coal Mine. It could reduce the water inflow in the coal face and put an end to the phenomenon of the abnormal water flow. Also the water inflow in the coal face in the range of $820 \sim 940 \mathrm{~m}$ was monitored in order to reflect control effect of the longitudinal connected fissure.

Field experiment of the longitudinal connected fissure control was important to control the advancement speed of the coal face during periodic weighting. The adjustment mining parameters of the coal face during periodic weighting are as follows: (1) Speed of the coal face advancement was increased from $11.2 \mathrm{~m} / \mathrm{d}$ to $16.0 \mathrm{~m} / \mathrm{d}$. (2) Setting load of the hydraulic support was increased to the $92 \%$ of maximum support resistance. (3) Mining height of the coal face was lowered $1.2 \mathrm{~m}$ before a sign of water inflow appeared in the coal face. At the same time, maintenance, shift change, and other works should be avoided during periodic weighting because these works need to stop the advancement in the coal faces.

Monitoring results of water inflow before and after adjustment of coal face parameters in coal face 31104 were shown (Figure 15). Figure 15(a) shows the monitoring result after adjustment of the coal face parameters, and Figure 15(b) shows the monitoring result before adjustment of the coal face parameters in the previous water-rich area. The water inflow was reduced overall in water-rich area after adjustment of coal face mining parameters, and the phenomenon of the abnormal water flow did not appear (Figure 15). The maximum water inflow $\left(80 \sim 104 \mathrm{~m}^{3} / \mathrm{h}\right)$ appeared in the periodic weighting, and this level of water inflow would not affect production. However, the minimum water inflow was higher than water inflow before adjustment of coal face parameters. It was deduced that the increase in the amount of exudation was caused by the increase in water 
sequestration after the longitudinal connected fissures were closed.

\section{Conclusion}

This paper studies the evolution law of longitudinal connected fissures in a shallowly buried coal faces with thin bedrock in the Jinjie Coal Mine, China. To understand the evolution of longitudinal connected fissures, theoretical analysis, numerical simulation, and field tests were conducted. The paper describes the evolution of longitudinal connected fissures in a shallowly buried coal face with thin bedrock and suggests control measures.

On the basis of field observations, physical simulation, theoretical analysis, and monitoring results, evolution of longitudinal connected fissures in a shallowly buried coal face with thin bedrock takes place in four stages: the fissure inoculation stage prior to periodic weighting, the stage of fissure expansion after periodic weighting, the stage of rapid fissure closure caused by breakage of the key block, and the stage of fissure compaction caused by rotation of the key rock. Gradual expansion of the fissure caused by rotational deformation of the key rock is the main factor in generation of sand bursts and water bursts.

Rapid closure of longitudinal connected fissures is caused by breakage of the key rock in the coal face with shallowly buried thin bedrock. Increasing the holding power of the hydraulic support and support area can control and delay fissure opening. At the same time, the coal face should be advanced as fast as possible through the stage of fissure expansion to prompt rapid closure of fissures, which can reduce the danger of sand-burst and water-burst accidents.

In this study, we describe the evolution of longitudinal connected fissures in a shallowly buried coal face with thin bedrock and suggest control measures. Suitable control measures can significantly slow down or eliminate the occurrence of sand-burst accidents, water-burst accidents, and abnormal increase in water inflow. The results of this study are of great significance for safe, environmentally friendly operation of mines under this type of geological conditions.

\section{Data Availability}

The data used to support the findings of this study are available from the corresponding author upon request.

\section{Conflicts of Interest}

The authors declare that there are no conflicts of interest regarding the publication of this paper.

\section{Acknowledgments}

This work was supported by the National Natural Science Foundation of China (Grant nos. 51604094 and 51674098) and China Postdoctoral Science Foundation (2019M662495). The authors thank Lucy Muir, Ph.D., from Liwen Bianji, Edanz
Editing China (http://www.liwenbianji.cn/ac), for editing the English text of a draft of this manuscript.

\section{References}

[1] Y. Zhang, H. Zhang, and P. Chen, "Visual exploration of fissure field of overburden and rock," Journal of China Coal Society, vol. 33, no. 11, pp. 1216-1219, 2008, in Chinese.

[2] Y. F. Ren, Y. Ning, and Q. X. Ji, "Physical analogous simulation on the characteristics of overburden breakage at shallow longwall coalface," Journal of China Coal Society, vol. 38, no. 1, pp. 61-66, 2013, in Chinese.

[3] J. Kim, R. Parizek, and D. Elsworth, "Evaluation of fullycoupled strata deformation and groundwater flow in response to longwall mining," International Journal of Rock Mechanics and Mining Science \& Geomechanics Abstracts, vol. 34, no. 8, pp. 1187-1199, 1997.

[4] P. Wang, L. Jiang, J. Jiang, P. Zheng, and W. Li, "Strata behaviors and rock-burst-inducing mechanism under the coupling effect of a hard thick stratum and a normal fault," International Journal of Geomechanics, vol. 18, no. 2, 2018.

[5] S. Wang, Coal Accumulating and Coal Resource Evaluation of Ordos Basin, China Coal Industry Publishing House, Beijing, China, 1996.

[6] L. Fan, "Underground water seepage caused by coal mining and its prevention and control measures in north Shaanxi Region," Min Saf Environ Prot, vol. 34, no. 5, pp. 62-64, 2007.

[7] S. M. Wang, Q. X. Huang, L. M. Fan et al., "Study on overburden aquclude and water protection mining regionazation in the ecological fragile mining area," Journal of China Coal Society, vol. 35, no. 1, pp. 7-13, 2010, in Chinese.

[8] M. G. Qian, J. L. Xu, and X. X. Miao, "Green technique in coal mining," Journal of China University of Mining \& Technology, vol. 32, no. 4, pp. 343-348, 2003, in Chinese.

[9] Z. Wang, H. Zhou, and H. Xie, "Research on fractal characterization of mined crack network evolution in overburden rock stratum under deep mining," Rock and Soil Mechanics, vol. 30, no. 8, pp. 2403-2408, 2009.

[10] H. Xie, Y. Ju, F. Gao, M. Gao, and R. Zhang, "Groundbreaking theoretical and technical conceptualization of fluidized mining of deep underground solid mineral resources," Tunnelling and Underground Space Technology, vol. 67, pp. 68-70, 2017.

[11] Z. Zhang, R. Zhang, H. Xie, and M. Gao, “The relationships among stress, effective porosity and permeability of coal considering the distribution of natural fractures: theoretical and experimental analyses," Environmental Earth Sciences, vol. 73, no. 10, pp. 5997-6007, 2015.

[12] Z. Zhang, R. Zhang, H. Xie, M. Gao, and J. Xie, "Mininginduced coal permeability change under different mining layouts," Rock Mechanics and Rock Engineering, vol. 49, no. 9, pp. 3753-3768, 2016.

[13] Z. Zhang and J. Nemcik, "Fluid flow regimes and nonlinear flow characteristics in deformable rock fractures," Journal of Hydrology, vol. 477, pp. 139-151, 2013.

[14] Z. Zhang, J. Nemcik, Q. Qiao, and X. Geng, "A model for water flow through rock fractures based on friction factor," Rock Mechanics and Rock Engineering, vol. 48, no. 2, pp. 559-571, 2014.

[15] Z. Zhang, N. Jan, T. Ren, and J. Zhang, "Influence of void space on microscopic behavior of fluid flow in rock joints," International Journal of Mining Science and Technology, vol. 24, no. 3, pp. 335-340, 2014. 
[16] X. Yu, B. Zhao, and G. Zhao, "Damage controls mode of mining subsidence about Shaanbei Jurassic Coalfield in China," Gospodarka Surowcami Mineralnymi-Mineral Resources Management, vol. 24, no. 3, pp. 51-59, 2008.

[17] Y. Tan, W. Guo, E. Bai, and D. Yang, "The height of fractured zones caused by strip Wongawilli mining in a shallow buried coal seam underlying a hard roof," Current Science, vol. 115, no. 7, pp. 1387-1392, 2018.

[18] Y. Lu and L. Wang, "Numerical simulation of mining-induced fracture evolution and water flow in coal seam floor above a confined aquifer," Computers and Geotechnics, vol. 67, pp. 157-171, 2015.

[19] B. Huang, S. Chen, and X. Zhao, "Hydraulic fracturing stress transfer methods to control the strong strata behaviors in gobside gateroads of longwall mines," Arabian Journal of Geosciences, vol. 10, no. 11, 2017.

[20] B. Huang, C. Liu, and J. Xu, "Research on through degree of overlying strata fracture fissure induced by mining," Journal of China University of Mining \& Technology, vol. 39, no. 1, pp. 45-49, 2010, in Chinese.

[21] B. Huang, C. Liu, and J. Xu, "Effect of little fault in coal face on water conducted fissure height," Journal of China Coal Society, vol. 34, no. 10, pp. 1316-1321, 2009, in Chinese.

[22] B. Huang, F. Liu, and Y. Wang, "Development of water conductive fissures in hidden reversed fault in thinning-out overlying strata of a stope," Journal of Mining \& Safety Engineering, vol. 27, no. 3, pp. 377-381, 2010.

[23] B. Huang and Y. Wang, "Roof weakening of hydraulic fracturing for control of hanging roof in the face end of high gassy coal longwall mining: a case study," Archives of Mining Sciences, vol. 61, no. 3, pp. 601-615, 2016.

[24] Y. Sun, "The study of the overburden damage movement law of the shallow buried coal seam of thin base rock," Journal of Anhui Institute of Architecture, vol. 17, no. 2, pp. 66-73, 2009.

[25] Q. Huang, K. Huang, and M. Zhao, "Research on roof structure and support resistance during first periodic weighting in shallow group coal seams," Journal of Mining \& Safety Engineering, vol. 35, no. 5, pp. 940-945, 2018.

[26] Q. Huang, J. Cao, and Y. He, "Analysis of roof structure and support load of mining face under ultra-close goaf in shallow multiple seams," Chinese Journal of Rock Mechanics and Engineering, vol. 37, no. S1, pp. 3153-3159, 2018, in Chinese. 


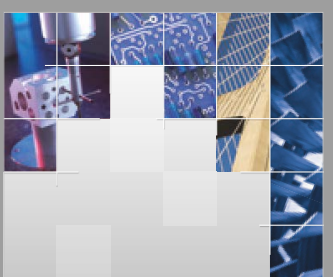

\section{Enfincering}
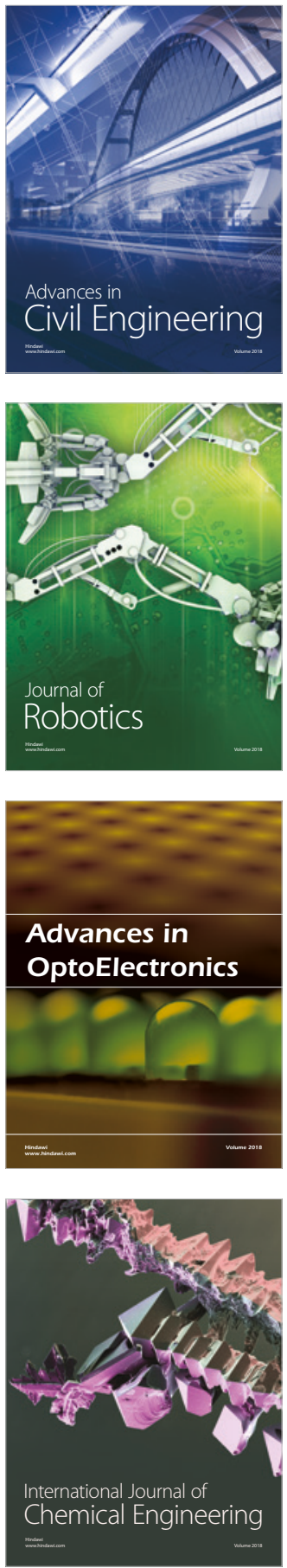

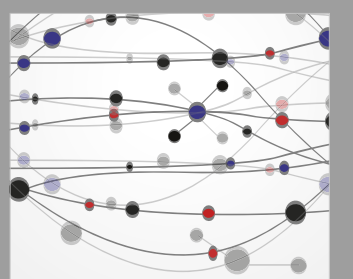

\section{Rotating \\ Machinery}

The Scientific World Journal

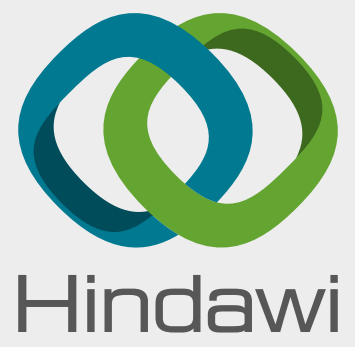

Submit your manuscripts at

www.hindawi.com
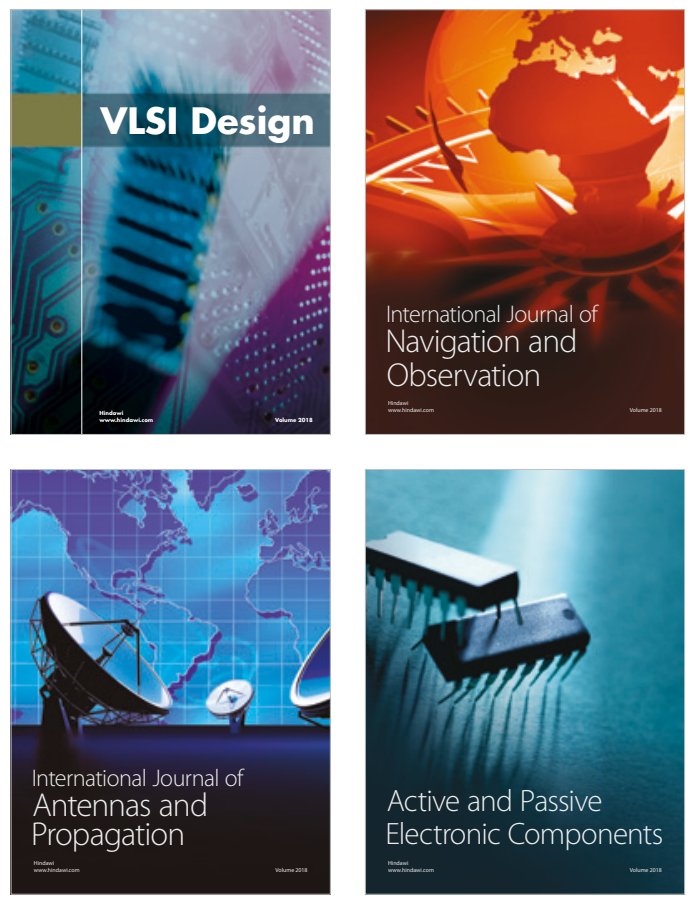
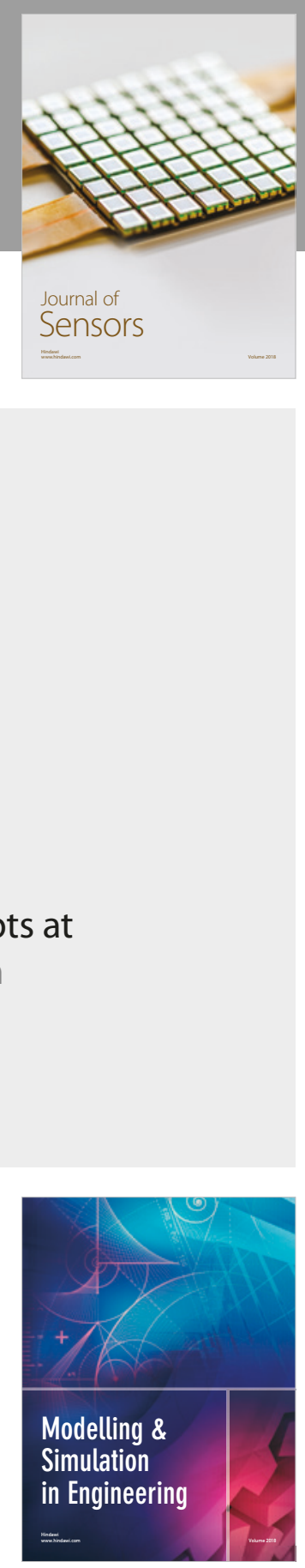

\section{Advances \\ Multimedia}
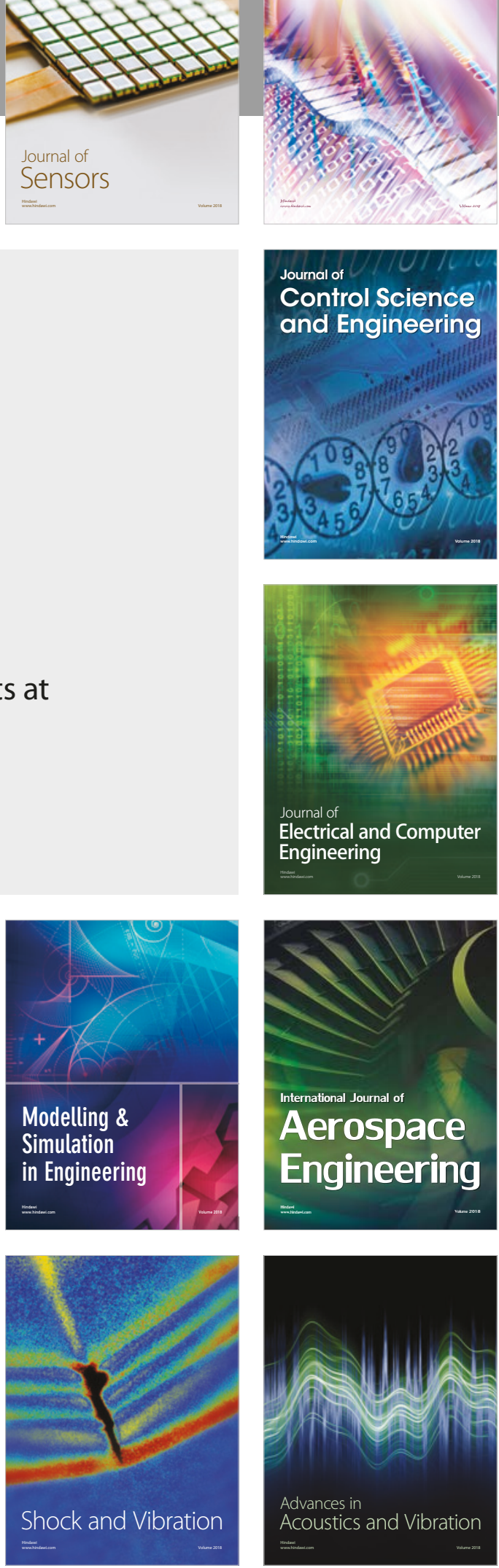